\title{
Dopamine-Regulated Adrenocorticotropic Hormone Secretion in Lactating Rats: Functional Plasticity of Melanotropes
}

\author{
Márk Oláh ${ }^{\mathrm{a}}$ Pálma Fehér ${ }^{\mathrm{b}}$ Zsófia $\mathrm{Ihm}^{\mathrm{a}}$ Ildikó Bácskay $^{\mathrm{b}}$ Timea Kiss $^{\mathrm{b}}$ \\ Marc E. Freeman ${ }^{c}$ György M. Nagy ${ }^{a}$ Miklós Vecsernyés ${ }^{b}$ \\ ${ }^{a}$ Neuromorphological and Neuroendocrine Research Laboratory, Department of Human Morphology \\ and Developmental Biology, Hungarian Academy of Sciences and Semmelweis University, Budapest, and \\ ${ }^{b}$ Pharmaceutical Technology, Faculty of Pharmacy, University of Debrecen, Debrecen, Hungary; ${ }^{\mathrm{C}}$ Department of \\ Biological Science, Program in Neuroscience, The Florida State University, Tallahassee, Fla., USA
}

\section{Key Words}

Lactation - Intermediate lobe $\cdot$ Adrenocorticotropic hormone $\cdot \alpha$-Melanocyte-stimulating hormone $\cdot$

Dopamine

\begin{abstract}
Pro-opiomelanocortin (POMC) is processed to adrenocorticotropic hormone (ACTH) and $\beta$-lipotropin in corticotropes of the anterior lobe, and to $\alpha$-melanocyte-stimulating hormone $(\alpha-M S H)$ and $\beta$-endorphin in melanotropes of the intermediate lobe (IL) of the pituitary gland. While ACTH secretion is predominantly under the stimulatory influence of the hypothalamic factors, hormone secretion of the IL is tonically inhibited by neuroendocrine dopamine (NEDA) neurons. Lobe-specific POMC processing is not absolute. For example, $D_{2}$ type DA receptor (D2R)-deficient mice have elevated plasma ACTH levels, although it is known that corticotropes do not express D2R(s). Moreover, observations that suckling does not influence $\alpha$-MSH release, while it induces an increase in plasma ACTH is unexplained. The aim of the present study was to investigate the involvement of the NEDA system in the regulation of ACTH secretion and the
\end{abstract}

participation of the IL in ACTH production in lactating rats. Untreated and estradiol $\left(E_{2}\right)$-substituted ovariectomized (OVX) females were also studied. The concentration of ACTH in the IL was higher in lactating rats than in OVX rats, while the opposite change in $\alpha$-MSH level of the IL was observed. DA levels in the IL and the neural lobe were lower in lactating rats than in OVX rats. Suckling-induced ACTH response was eliminated by pretreatment with the DA receptor agonist, bromocriptine (BRC). Inhibition of DA biosynthesis by $\alpha$ methyl-p-tyrosine $(\alpha \mathrm{MpT})$ and blockade of $\mathrm{D} 2 \mathrm{R}$ by domperidone (DOM) elevated plasma ACTH levels, but did not influence plasma $\alpha$-MSH levels in lactating rats. The same drugs had opposite effects in OVX and OVX $+E_{2}$ animals. In lactating mothers, BRC was able to block ACTH responses induced by both $\alpha M p T$ and DOM. Surgical denervation of the IL elevated basal plasma levels of ACTH. Taken together, these data indicate that melanotropes synthesize ACTH during lactation and its release from these cells is regulated by NEDA neurons.

Copyright $\odot 2009$ S. Karger AG, Basel

\section{KARGER}

Fax +4161306 1234

E-Mail karger@karger.ch

www.karger.com
(C) 2009 S. Karger AG, Basel

$0028-3835 / 09 / 0904-0391 \$ 26.00 / 0$

Accessible online at:

www.karger.com/nen
György M. Nagy, Neuromorphological and Neuroendocrine Laboratory

Department of Human Morphology and Developmental Biology

Hungarian Academy of Sciences and Semmelweis University

Tüzoltó u. 58, HU-1094 Budapest (Hungary)

Tel. +361215 6920, Fax +36 1215 3064, E-Mail nagy-gm@ana2.sote.hu 


\section{Introduction}

Pro-opiomelanocortin (POMC) is processed to adrenocorticotropic hormone $(\mathrm{ACTH})$ and $\beta$-lipotropin $(\beta$ $\mathrm{LPH})$ in the corticotropes of the anterior lobe (AL), and to $\alpha$-melanocyte-stimulating hormone $(\alpha-\mathrm{MSH})$ and $\beta$ endorphin $(\beta$-END) in the melanotropes of the intermediate lobe (IL) of the rat pituitary gland $[1,2]$. The posttranslational processing of POMC to yield a variety of peptides is effected by prohormone convertases (PCs). $\mathrm{PCl}$ is strongly expressed in the AL, cleaving POMC to yield $\mathrm{ACTH}$ and $\beta$-LPH. In the IL, following PC1 processing of POMC, PC2 cleaves ACTH into $\alpha-\mathrm{MSH}$ and corticotropin-like IL peptide $[3,4]$. While PC2 must interact with the chaperone molecule $7 \mathrm{~B} 2$ to generate active $\mathrm{PC} 2$, this is not the case for PC1. Therefore, 7B2 is a specific binding or chaperone protein for PC2. The processing and the secretion of ACTH and $\alpha-\mathrm{MSH}$ is under hypophysiotropic regulation, being stimulated by corticotropin-releasing factor produced by the hypothalamic paraventricular nuclei (PVN) [5]. On the other hand, $\mathrm{ACTH}$ secretion from the AL is inhibited by glucocorticoids released from the adrenal glands [6]. In the IL, $\alpha$ MSH processing and secretion is controlled by hypothalamic dopamine (DA) released by subpopulations of the hypothalamic neuroendocrine DAergic (NEDA) neurons [7]. Consistent with this differential control of POMC regulation in the IL and the AL, glucocorticoid receptors are present in the latter but not the former [8]. On the other hand, $\mathrm{D}_{2}$ type DA receptors (D2Rs) are expressed in lactotropes of the AL but also in melanotropes of the IL, allowing for tonic hypothalamic inhibition of prolactin (PRL) and $\alpha-\mathrm{MSH}$ secretion by separate subpopulations of NEDA neurons $[9,10]$.

NEDA neurons controlling both AL and IL are located in the anterior periventricular region and the arcuate nucleus of the hypothalamus and can be divided into three groups, based upon their sites of projections as well as their regulatory functions. Perikarya of tuberoinfundibular DAergic (TIDA) neurons located in the caudal portion of the arcuate nucleus project to the external layer of the median eminence [11]. DA produced by these neurons is considered to be the major tonic regulator of PRL secretion $[12,13]$. TIDA activity is different in female rats than in males and the secretory pattern of DA in females depends on the ovarian steroid hormone background [14, 15]. It is also known that neuronal activity of TIDA neurons decreases during lactation [16-18]. Tuberohypophysial DAergic (THDA) neurons originate from the rostral portion of the arcuate nucleus and project to both the neural lobe (NL) and IL passing through the internal zone of the median eminence [19]. While the physiological role of these neurons is not entirely known, it is worth mentioning that in addition to the TIDA system, they also participate in the control of the PRL secretory response induced by the suckling stimulus [20], which is likely related to osmosensitive properties. In addition to the aforementioned systems, DAergic neurons in the rostral periventricular region (periventriculohypophysial DAergic, PHDA) exclusively innervate the IL and play a dominant inhibitory role in the processing and secretion of the IL peptides [4, 21].

Recent studies show that, under certain conditions, disproportionately large amounts of ACTH can be produced in the IL, leading to elevation of plasma ACTH levels. For example, D2R gene-deficient mice, besides displaying hyperprolactinemia [22-24], overexpress $\mathrm{PC1}$ in the IL and have elevated serum levels of ACTH, leading to a Cushing's-like syndrome [25]. Recently, 7B2-null mice have also been generated [26], in which PC2 is inactive, leading to the failure to generate $\alpha-\mathrm{MSH}$ in the IL. This results in a very high level of ACTH, similar to that seen in pituitary Cushing's disease. As mentioned above, production of POMC-related peptides in the IL is controlled by DA and 7B2-null mice have DA levels reduced to one quarter of the normal levels. It is presumed that a diminished pool of DA in the nerve endings in both the IL and the NL of 7B2-null mice is a likely causative factor in the enhanced secretion of ACTH [27]. However, strain-dependent differences must be taken into account when comparing different lines of either D2R or 7B2 knockout mice [24].

Only a few studies have examined the regulation of $\mathrm{ACTH}$ secretion during lactation. It is well known that in parallel with the PRL response, suckling causes ACTH secretion without having any effect on plasma $\alpha-\mathrm{MSH}$ concentrations [28-31]. At the same time, lactation is associated with a reduction or absence of ACTH $[32,33]$ and PRL $[34,35]$ responses to different stressful stimuli, even though basal concentrations of the same hormones are elevated [32]. The role of hypothalamic DA in these animal models and its role in physiological processes like suckling stimulus-induced ACTH response have not been explored fully.

The aim of our present studies was to investigate the possible involvement of hypophysiotropic DA in the regulation of ACTH secretion in lactating rats. We measured concentrations of ACTH and $\alpha-\mathrm{MSH}$ in the AL and the IL as well as DA and DOPAC in the IL and the NL of lactating and of ovariectomized (OVX) female rats. In addition, we measured plasma levels of ACTH and $\alpha-\mathrm{MSH}$ of 
lactating rats, of OVX and of $17 \beta$-estradiol $\left(\mathrm{E}_{2}\right)$-substituted OVX animals using physiological (suckling stimulus) and pharmacological (DA receptor and synthesis inhibition) as well as surgical (posterior pituitary denervation, PPD) interventions.

\section{Materials and Methods}

\section{Animals}

Primiparous Sprague-Dawley lactating rats (220-250 g b.w.) were used at days 7-11 of lactation. Litter size was standardized to 8 from the second postpartum day. Ovariectomy of cycling females was performed 7 days before any treatments. A group of OVX rats $(n=6)$ received subcutaneous implants of $E_{2}$ (containing $150 \mu$ g cyclodextrin-encapsulated $\mathrm{E}_{2}$; Sigma-Aldrich, Budapest, Hungary) capsules (10-mm-long silastic tube, internal diameter: $1 \mathrm{~mm}$ ) 3 days prior to experimentation [36]. The animals were housed in a temperature-controlled room $\left(21-23^{\circ} \mathrm{C}\right)$ with alternating cycles of $14 \mathrm{~h}$ light and $10 \mathrm{~h}$ darkness. Standard rat chow and water was available ad libitum. All experiments were conducted in accordance with the Guide of Permission (No. 1894/003/2004) for Care and Use of Laboratory Animals.

\section{Drugs and Sampling}

Two or 3 days prior to the experimentation, a cannula was implanted into the right jugular vein (silicon tubing, Dow Corning Corp., Midland, Mich., USA) of the animals for blood sampling. Dams were separated from their pups before experiments for a 4 hour period. After the 4-hour separation, the animals were administered an intravenous injection of either domperidone (DOM, a D2R antagonist; Sigma-Aldrich; $20 \mu \mathrm{g} /$ rat i.v.) or $\alpha$ methyl-p-thyrosine ( $\alpha \mathrm{MpT}$; Sigma-Aldrich; $25 \mathrm{mg} / \mathrm{kg}$ b.w. i.v.). Lactating, OVX and $\mathrm{E}_{2}$-substituted OVX animals were treated and venous blood samples were collected for PRL, $\alpha-\mathrm{MSH}$ and ACTH measurements. Bromocriptine (BRC; 3 mg/kg b.w.; SigmaAldrich) or saline were also administered subcutaneously $60 \mathrm{~min}$ prior to resumption of the suckling stimulus or the administration of $\alpha \mathrm{MpT}$ or DOM.

\section{Posterior Pituitary Denervation}

In lactating dams, an L-shaped, rotating wire knife with the blade $110^{\circ}$ to the shaft was used for denervation of the posterior pituitary (IL and NL) as described previously [37]. For sham operation, the knife was lowered $5 \mathrm{~mm}$ beneath the surface of the skull. Following PPD, animals received 1-desamino-8-D-arginine vasopressin (dDAVP, 2 mg/l, Adiuretin-SD; SPOFA, Prague, Czech Republic) in water for the treatment of ensuing diabetes insipidus (sham animals received tap water only). Five to 7 days after the PPD procedure, mothers were separated from their pups for $4 \mathrm{~h}$. Blood samples were obtained through the jugular cannula and plasma ACTH was measured as detailed below.

High-Pressure Liquid Chromatography Coupled with Electrochemical Detection for Measurement of DA and DOPAC

Animals were euthanized by decapitation, then the IL and NL were dissected out of the pituitary gland, and placed immediately on dry ice. Catecholamine and metabolite levels in these tissues were determined within 2 weeks, using the method described previously [37]. Briefly, homogenization was found in 200-500 $\mu$ l of $0.2 \mathrm{~N}$ perchloric acid containing EGTA $(0.025 \mathrm{mM})$ by ultrasound. After centrifugation $\left(10,300 \mathrm{~g}, 15 \mathrm{~min}, 4^{\circ} \mathrm{C}\right), 20 \mu \mathrm{l}$ of supernatant was injected into a Shimadzu HPLC apparatus using an autosampler and built-in integrator program, combined with ECD (ESA Coulochem II). A reverse-phase column (Wakosil II C18, $150 \times$ $4.6 \mathrm{~mm}, 5 \mu \mathrm{m}$, SGE) was employed. The eluate was $5 \%$ acetonitrile in water containing sodium phosphate $\left(\mathrm{NaH}_{2} \mathrm{PO}_{4} ; 0.075 \mathrm{M}\right)$, octanesulfonic acid sodium salt $(1.7 \mathrm{~mm})$, EDTA $(0.1 \mathrm{mM})$ and triethylamine $(100 \mu \mathrm{l} / \mathrm{l})$. The $\mathrm{pH}$ of the mobile phase was adjusted to 3.0 with phosphoric acid. The interassay variation of the determinations was $8-15 \%$ for DA and DOPAC. The protein content of the pellet was determined by Lowry's method [38]. Catecholamine concentrations are presented as nanograms per milligram protein.

\section{Hormone Determinations}

Blood samples were collected into ice-cold Eppendorf tubes containing $20 \mu \mathrm{l} 20 \%$ sodium EDTA and centrifuged at 3,000 $\mathrm{rpm}$ for $20 \mathrm{~min}$ at $-4^{\circ} \mathrm{C}$. Plasma was then harvested and stored at $-20^{\circ} \mathrm{C}$ for assay of pituitary hormones.

Individual anterior and intermediate lobes of pituitaries were homogenized by ultrasound and centrifuged in $0.5 \mathrm{ml}$ of $1 \mathrm{~N} \mathrm{HCl}$ at 5,000 rpm for $15 \mathrm{~min}$. The lyophilized supernatant was preserved for radioenzymatic measurement.

PRL was measured by RIA using the materials kindly provided by the National Hormone and Pituitary Program (Rockville, Md., USA) [39]. Tissue samples were obtained from lactating rats (continuously suckled until days 5-10 of lactation) and OVX females (7 days after surgery). Plasma and tissue levels of $\alpha-\mathrm{MSH}$ [40] and ACTH [41] were determined by specific RIAs. For measurement of plasma $\alpha-\mathrm{MSH}$, proteins were denaturated by adding $96 \%$ of ethanol to each sample then centrifuged. The supernatants were partially evaporated under $\mathrm{N}_{2}$ environment. The antiserum used in the RIA revealed cross-reactivities as follows: $\mathrm{ACTH}_{1-13^{-}}$ $\mathrm{NH}_{2} \quad 68 \% ; \mathrm{ACTH}_{1-24}$ 0.2\%; $\mathrm{ACTH}_{1-39}-\mathrm{ACTH}_{1-32}-\mathrm{ACTH}_{1-16^{-}}$ $\mathrm{ACTH}_{1-10}-\mathrm{ACTH}_{1-8}-\mathrm{ACTH}_{4-10}-\mathrm{ACTH}_{11-24}, \beta-\mathrm{END}, \beta-\mathrm{LPH}, \gamma_{3^{-}}$ $\mathrm{MSH}$, and $\mathrm{N}$-terminal fragment of human POMC $<0.01 \%$. The detection limit of the assay was $2-3 \mathrm{pg} / \mathrm{sample}$. The ACTH antibody (No. 8514), directed against the midportion of the h$\mathrm{ACTH}_{1-39}$ molecule, was raised in rabbit in the Institute of Experimental Medicine, Hungarian Academy of Sciences (Budapest, Hungary). The antibody is highly specific, showing $0.2 \%$ cross-reaction with $\alpha-\mathrm{MSH}$, and no significant cross-reaction with $\gamma$-MSH, corticotropin-like intermediate lobe peptide, $\mathrm{ACTH}_{11-24}, \mathrm{ACTH}_{25-39}, \mathrm{ACTH}_{1-14}$, and $\mathrm{ACTH}_{1-19}$. All samples were measured in duplicate and from a particular experiment in the same assay. The intra- and interassay coefficients of variations were $<10 \%$.

\section{Statistical Analysis}

All results are expressed as means \pm SEM. Statistical analysis of the data was performed using one- and two-way ANOVA and Dunnet's multiple range post hoc test (StatSoft STATISTICA 7.1). 


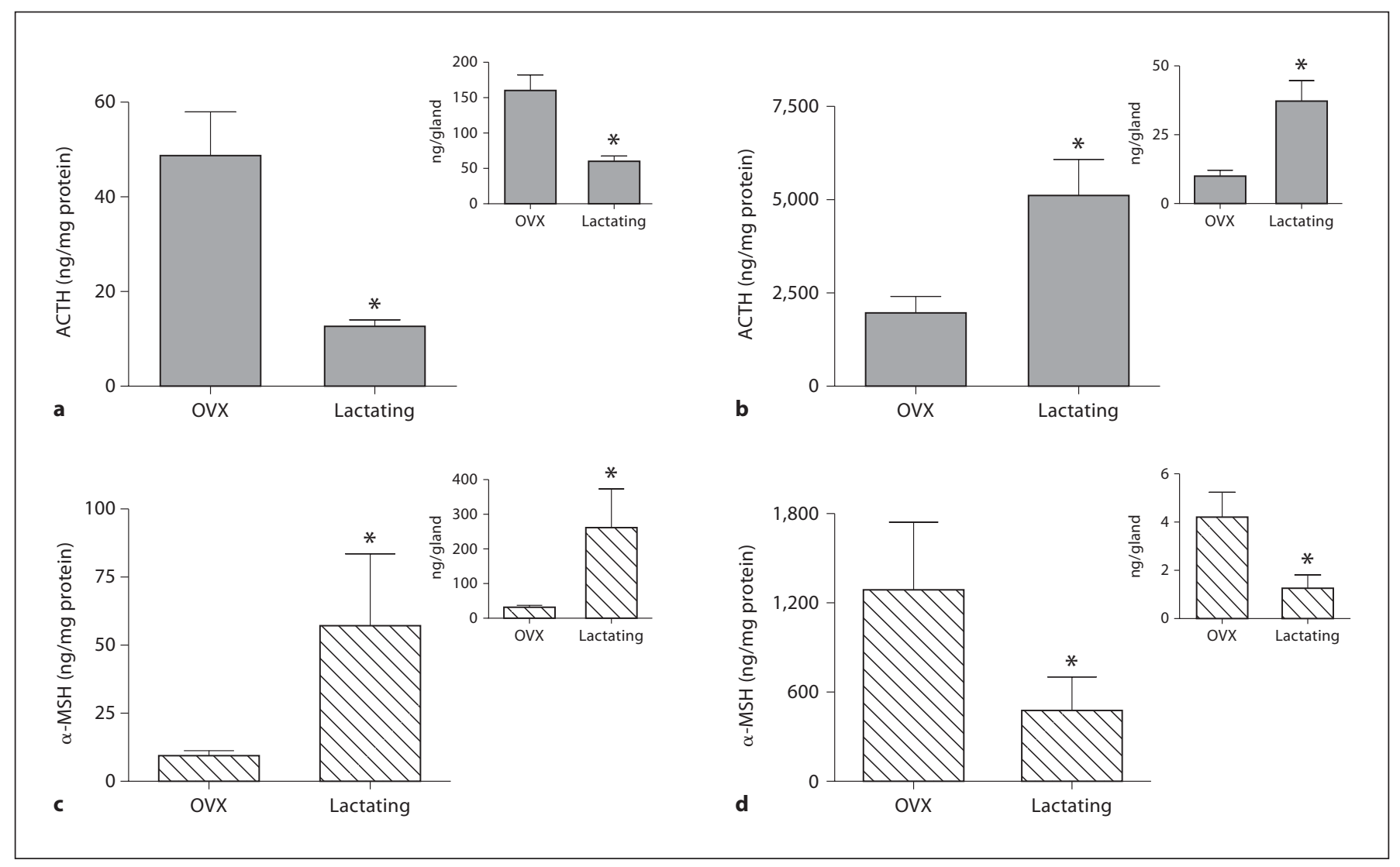

Fig. 1. Comparisons of $\mathrm{ACTH}(\mathbf{a}, \mathbf{b})$ and $\alpha-\mathrm{MSH}(\mathbf{c}, \mathbf{d})$ concentration (expressed in $\mathrm{ng} / \mathrm{mg}$ protein) in the AL (a, c) and the IL $(\mathbf{b}, \mathbf{d})$ detected in OVX versus lactating female rats (separated from their pups for $4 \mathrm{~h}$ ). Content (expressed in ng/gland) of ACTH and $\alpha$-MSH can also be seen in the inserts of each graph. Values represent the mean \pm SEM of 6 rats per group. Statistical significance compared to OVX group: ${ }^{*} \mathrm{p}<0.05$.

\section{Results}

Comparison of Concentration as well as Content of $A C T H$ and $\alpha-M S H$ in the AL and IL of the Pituitary Gland of Lactating versus OVX Female Rats

The highest concentration of ACTH was detected in the IL, being significantly higher in lactating rats than in OVX animals (fig. 1b). In the same animals, the ACTH concentration of the AL was more than two times higher in OVX rats than in lactating rats (fig. 1a). The concentration of $\alpha-\mathrm{MSH}$ was highest in the IL (fig. 1d) and the level of this peptide was significantly lower in samples obtained from lactating mothers compared to those from OVX animals. The opposite was observed in the AL (fig. 1c) with higher levels of $\alpha-\mathrm{MSH}$ in lactating rats compared to OVX animals. It should be emphasized that the total amount (content) of both ACTH and $\alpha-\mathrm{MSH}$ (expressed as ng/ gland) is higher (about 5-10-12 and 8-9 times, respec- tively) in the AL compared to the IL (see inserts of fig. 1a, c) of OVX rats. The ratio between AL and IL ACTH decreases while the content of ACTH was still higher (about 1.5-2 times) in the AL of lactating mothers. As far as the content of $\alpha-\mathrm{MSH}$ is concerned (fig. 1c, d), an elevation in the $\mathrm{AL}$ and about a $50 \%$ reduction in the IL could be observed (the ratio increased to about 100-130).

The Level of DA and DOPAC in the IL and the NL of Lactating versus OVX Female Rats

To investigate a possible alteration in DAergic regulation of NL and IL that might contribute to the observed difference in ACTH levels of OVX compared to lactating rats, DA and DOPAC levels were measured in IL and NL extracts (table 1). DA content was about 6 - to 7 -fold lower in both the IL and the NL of lactating mothers compared to OVX female rats. The concentrations of DOPAC were also 3.5- to 6-fold higher in the IL and the NL (table 1). 

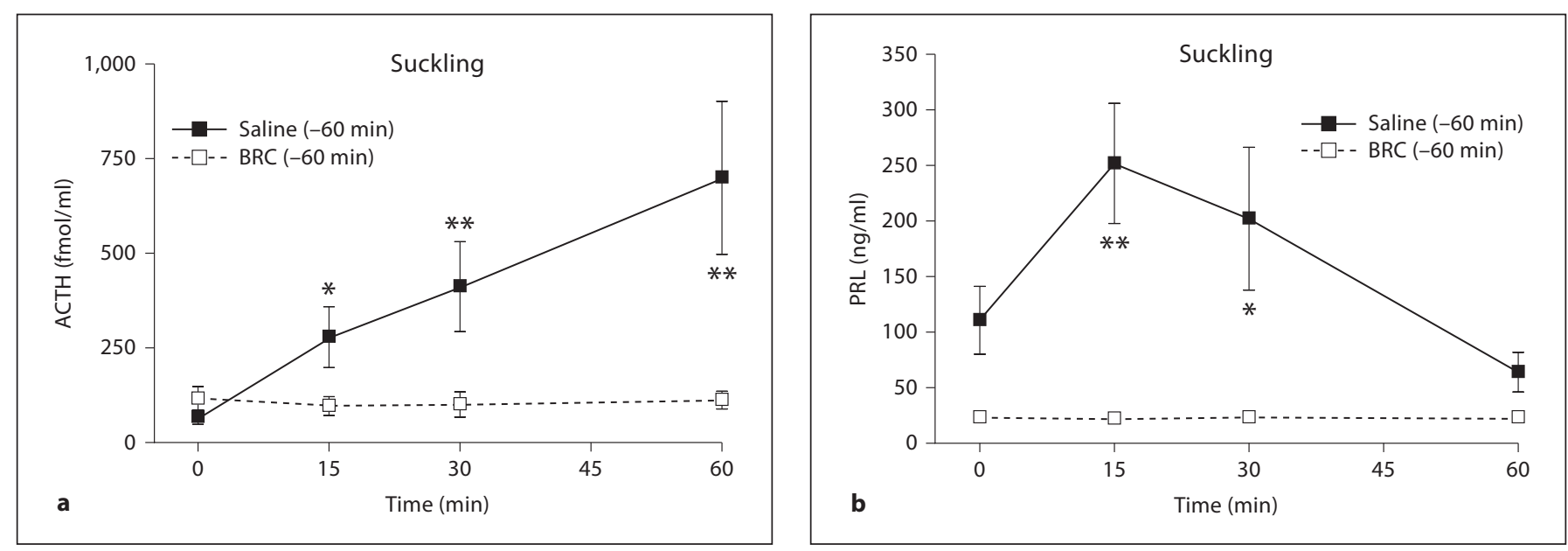

Fig. 2. BRC (3 mg/kg b.w. s.c.) pretreatment (-60 min) was able to inhibit both suckling-induced ACTH (a) and PRL (b) releases in lactating dams. Nursing was initiated by reuniting mothers and pups after a 4-hour separation period. Each value represents the mean \pm SEM of 6-8 mothers per group. Statistical significance compared to matched BRC-treated group: ${ }^{*} \mathrm{p}<0.05 ;{ }^{* *} \mathrm{p}<0.001$.

Table 1. Concentration of DA and DOPAC (ng/mg protein) in the IL and NL obtained from lactating (separated for $4 \mathrm{~h}$ ) and OVX female rats

\begin{tabular}{lll}
\hline & DA & DOPAC \\
\hline Lactating & & \\
IL & $1.81 \pm 0.04$ & $0.21 \pm 0.50$ \\
NL & $0.87 \pm 0.02$ & $0.11 \pm 0.03$ \\
OVX & & \\
IL & $13.30 \pm 2.13^{*}$ & $0.79 \pm 0.04^{*}$ \\
NL & $5.80 \pm 1.17^{*}$ & $0.65 \pm 0.06^{*}$ \\
\hline
\end{tabular}

Each value is the mean \pm SD of 6 animals. The asterisk indicates significance $(\mathrm{p}<0.05)$ between OVX and lactating groups.

\section{Effect of BRC on Suckling-Induced ACTH and PRL Responses}

Plasma concentrations of ACTH and PRL increased in response to the suckling stimulus. Pretreatment of rat mothers with the D2R agonist BRC completely prevented the ACTH and PRL secretory responses to the suckling stimulus (fig. 2a, b).

Effect of DOM and $\alpha M p T$ on Plasma Levels of PRL, $A C T H$ and $\alpha-M S H$ in Lactating-, OVX- and OVX + $E_{2}$-Treated Rats

Based upon the inhibitory effect of BRC on the suckling-induced ACTH release, we hypothesized that a DA- ergic mechanism is involved in these responses. Therefore, the effects of pharmacological manipulations of the NEDA system using $\alpha \mathrm{MpT}$ (a tyrosine hydroxylase inhibitor) and DOM (a selective D2R antagonist) on ACTH secretion in lactating rats were compared with the effect of these agents in OVX and $\mathrm{E}_{2}$-substitued OVX female rats. The basal levels of plasma PRL were higher in OVX $+\mathrm{E}_{2}$-substituted rats $(46.0 \pm 15.7 \mathrm{ng} / \mathrm{ml})$ than in OVX $(10.8 \pm 2.0)$ or lactating (14.5 \pm 7.1) animals following a 4-hour separation period. Administration of $\alpha \mathrm{MpT}$ significantly elevated ACTH levels (fig. 3a) as well as PRL levels (fig. 4a) in lactating rats. On the other hand, $\alpha \mathrm{MpT}$ had no influence on plasma $\alpha$-MSH levels (fig. 4c) in lactating dams. The same dose of $\alpha \mathrm{MpT}$ increased plasma PRL (fig. 4a) and $\alpha-\mathrm{MSH}$ (fig. 4c) but not ACTH (fig. 3a) in OVX as well as in OVX $+\mathrm{E}_{2}$-substituted female rats. Similar to effects of $\alpha \mathrm{MpT}$, DOM treatment elevated both plasma ACTH (fig. 3b) and PRL levels (fig. 4b) in lactating rats without an effect on plasma $\alpha$-MSH levels (fig. 4d). However, significant differences were observed only after $15 \mathrm{~min}$ of DOM injection in ACTH secretion in lactating dams compared to OVXand OVX $+\mathrm{E}_{2}$-treated groups (fig. $3 \mathrm{~b}$ ), although at later time points (30 and $60 \mathrm{~min}$ ) DOM elevated ACTH in OVX- and OVX $+\mathrm{E}_{2}$-treated groups. This indicated some differences between the inhibition of biosynthesis of DA $(\alpha \mathrm{MpT})$ and $\mathrm{D} 2 \mathrm{R}$ blockade $(\mathrm{DOM})$. In a manner similar to that seen with $\alpha \mathrm{MpT}$, treatment with $\mathrm{DOM}$ also resulted in an increase of plasma PRL in all three animal models (fig. 4b). This treatment also increased $\alpha-\mathrm{MSH}$ (fig. 4d) 


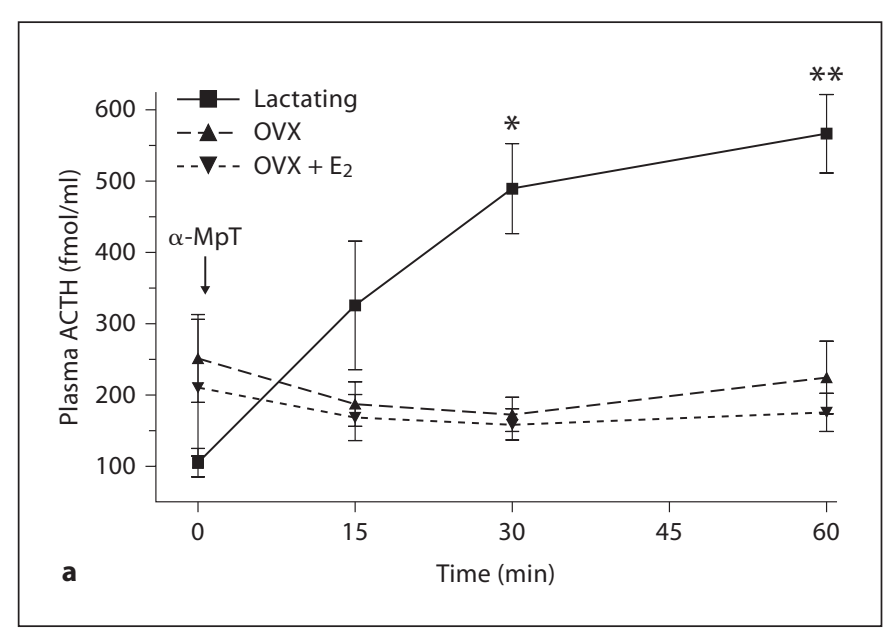

Fig. 3. a Inhibition of DA biosynthesis with $\alpha \mathrm{MpT}$ resulted in a distinct increase of plasma ACTH in lactating rats 30 and $60 \mathrm{~min}$ following the injection. At the same time, plasma ACTH was not elevated in OVX and $\mathrm{OVX} / \mathrm{E}_{2}$ females following the same treatment. Each value represents the mean \pm SEM of 5-6 animals per group. Statistical significance compared to matched OVX/OVX +

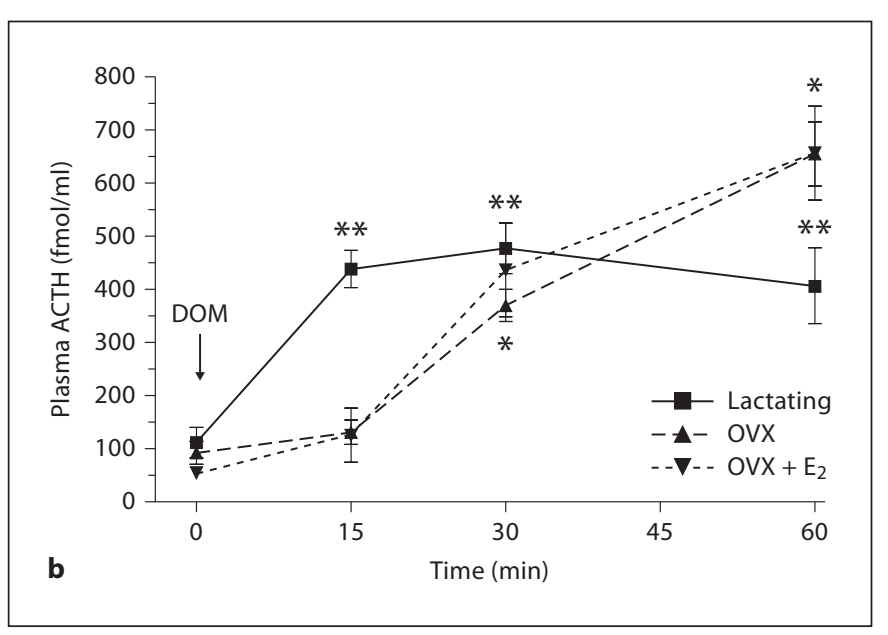

$\mathrm{E}_{2}$ group: ${ }^{*} \mathrm{p}<0.05 ;{ }^{* *} \mathrm{p}<0.001$. b A significant ACTH response could be detected in lactating rats $15 \mathrm{~min}$ after the administration of the peripheral D2R antagonist DOM $(20 \mu \mathrm{g} / \mathrm{kg}$ b.w. i.v.). Each value represents the mean \pm SEM of 5-6 animals per group. Statistical significance compared to OVX/OVX $+\mathrm{E}_{2}$ group: ${ }^{*} \mathrm{p}<$ $0.05 ;{ }^{* *} \mathrm{p}<0.001$. concentrations in the OVX and OVX $+\mathrm{E}_{2}$ groups. It should be mentioned that not only the basal level (vida supra), but also the $\alpha \mathrm{MpT}$-, and DOM-induced increases of plasma PRL were significantly higher in OVX $+\mathrm{E}_{2}$ compared to OVX animals (fig. 4a, b), while no such differences could be detected in case of the other two hormones (fig. 3a, b, fig. $4 c, d)$.

\section{Effect of BRC on DOM- and $\alpha M p T$-Induced ACTH and PRL Responses in Lactating Rats}

The role of DAergic transmission in the secretory responses of ACTH induced by either $\alpha \mathrm{MpT}$ or DOM was further clarified by the demonstration that D2R blocked both plasma PRL (fig. 5a, b) and ACTH (fig. 5c, d) responses in lactating rats.

\section{Effect of PPD on Plasma Levels of ACTH of Lactating Rats}

The level of ACTH was measured in the blood of intact and PPD lactating animals separated from their pups for 4 h. PPD elevated plasma ACTH levels (fig. 6). Based upon our previous experimental data [30] that PPD causes diabetes insipidus, daily water intake was doubled in denervated mothers; this was reversed by administration of dDAVP. Plasma ACTH levels were also measured in a subgroup of animals where diabetes insipidus was normalized. The elevation of plasma ACTH following PPD was not influenced by administration of dDAVP (fig. 6). Thus, we can conclude that the functional deficit in the production of neurosecretory materials is not related to the elevation of plasma level of ACTH.

\section{Discussion}

IL ACTH concentration and content is higher in lactating rats than in OVX rats, while IL $\alpha$-MSH shows an opposite pattern with higher concentrations in OVX rats than in lactating rats. Inhibition of DA biosynthesis by $\alpha \mathrm{MpT}$ and blockade of D2Rs by DOM significantly elevated plasma ACTH levels, but did not influence plasma $\alpha$-MSH levels in lactating rats. These drugs, however, had opposite effects in OVX and OVX $+\mathrm{E}_{2}$ animals, causing elevation in plasma $\alpha$-MSH levels but no change in ACTH levels. Moreover, in lactating mothers, BRC was able to block ACTH responses induced by either suckling, or $\alpha \mathrm{MpT}$ or DOM treatment. Much lower levels of DA and DOPAC were found in both the IL and NL of lactating than in OVX rats. Furthermore, surgical denervation of the posterior pituitary elevated basal levels of ACTH. Based on these observations, it seems very likely that hypothalamic NEDA neurons play a significant and previously unrecognized role in the regulation of ACTH secretion during lactation. 


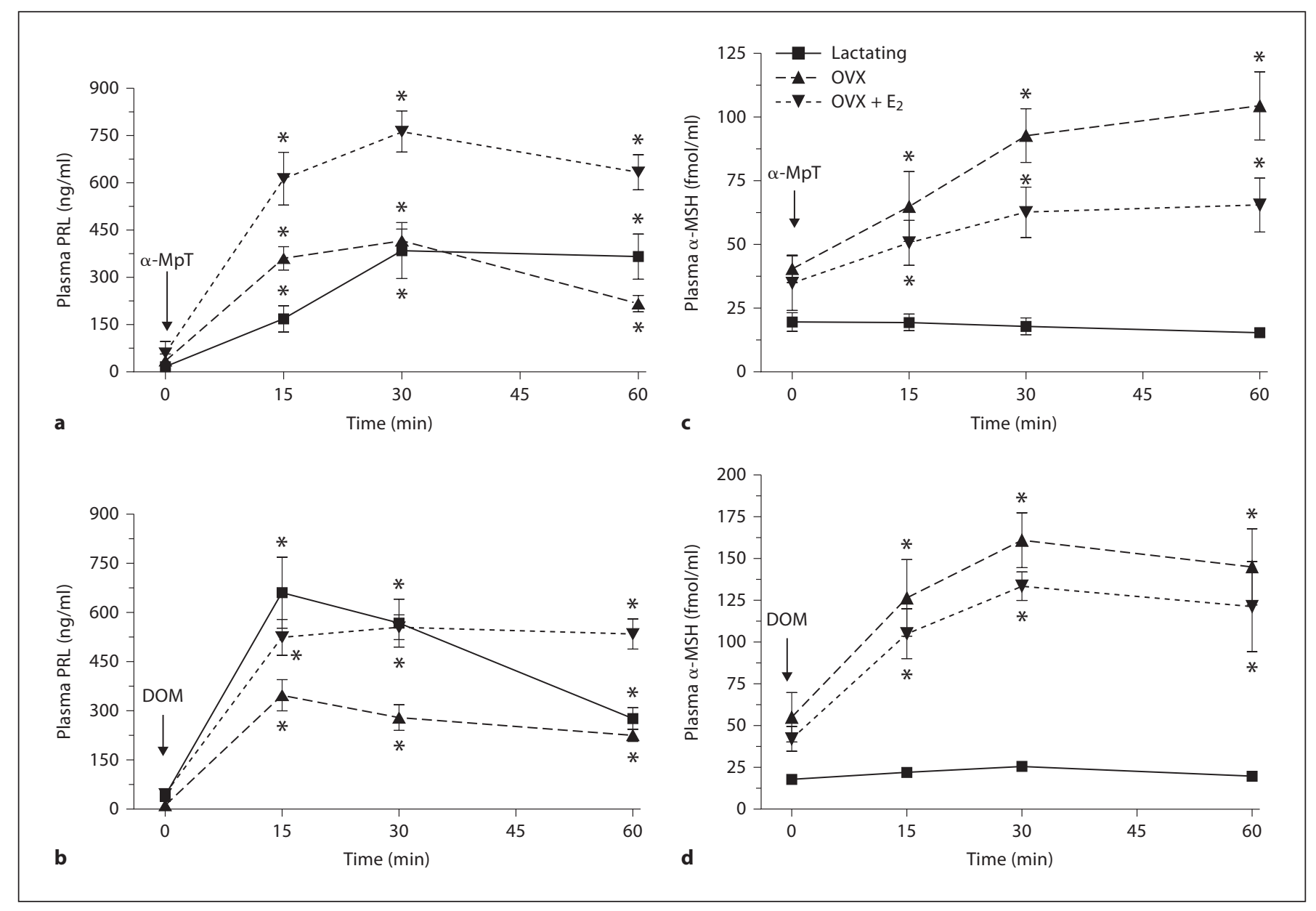

Fig. 4. a Administration of $\alpha \mathrm{MpT}(25 \mathrm{mg} / \mathrm{kg}$ b.w., i.v.) resulted in a significant elevation of plasma PRL in all three groups, nonsuckled (separated for $4 \mathrm{~h}$ ) lactating, OVX and OVX/E 2 measured 15, 30 and $60 \mathrm{~min}$ after the injection. Each value represents the mean \pm SEM of 5-6 rats per group. Statistical significance compared to matched 0 min sampling time: ${ }^{*} \mathrm{p}<0.05$. $\mathbf{b}$ Administration of DOM $(20 \mu \mathrm{g} / \mathrm{kg}$ b.w. i.v.) results in a significant elevation of plasma PRL in all three groups 15, 30 and 60 min after the injection. Each value represents the mean \pm SEM of 5-6 animals per group. Statistical significance compared to matched 0 min sampling time: ${ }^{*} \mathrm{p}<0.05$. c $\alpha \mathrm{MpT}$ treatment increases plasma level of $\alpha$ -
$\mathrm{MSH}$ in OVX- and OVX/E $/ \mathrm{E}_{2}$-treated animals, but it has no effect in lactating rats (separated for $4 \mathrm{~h}$ ). Each value represents the mean \pm SEM of 5-6 rats per group. Statistical significance compared to values detected in the lactating group: ${ }^{*} \mathrm{p}<0.05$. d Administration of DOM following a 4-hour separation period has no effect on plasma $\alpha-\mathrm{MSH}$ concentration in lactating rats, but in OVX and $\mathrm{E}_{2}$-substituted OVX animals, it results in a significant elevation of $\alpha-\mathrm{MSH}$ secretion. Each value represents the mean \pm SEM of 5-6 animals per group. Statistical significance compared to matched lactating group: ${ }^{*} \mathrm{p}<0.05$.
Our data show that both the concentration (ng/mg protein) and the content (ng/gland) of ACTH are lower in the AL of lactating versus OVX rats (fig. 1a), while an opposite trend is seen with respect to $\alpha$-MSH levels (fig. 1c). In light of the previously published elevated basal trough concentrations of ACTH and the blunted responses to stress [32], this may reflect increased rates of secretion of ACTH from the AL. However, taking into consideration the data obtained in the same experiment that the concentration as well as the content of ACTH is higher (fig. 1b), but the $\alpha-\mathrm{MSH}$ is lower (fig. 1d) in the IL of lactating mothers compared to OVX rats, it could be a change in the processing of POMC in the separate lobes of the pituitary gland. This conclusion is underlined by the fact that the levels of these two peptides are not independent from each other. ACTH is processed first, then 


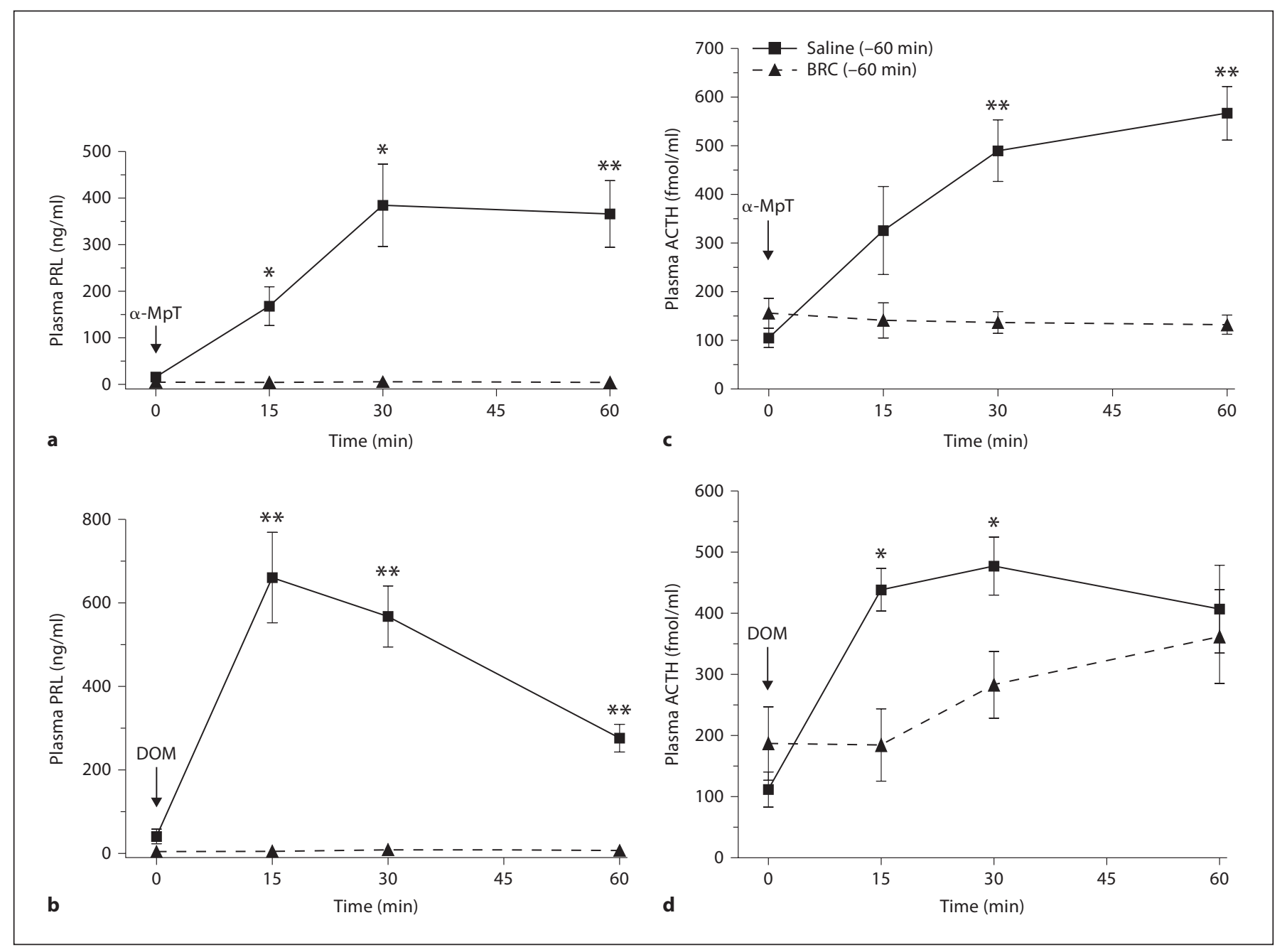

Fig. 5. Injection of BRC 60 min prior to administration of either $\alpha \mathrm{MpT}(\mathbf{a}, \mathbf{c})$ or $\mathrm{DOM}(\mathbf{b}, \mathbf{d})$ prevents elevation of plasma PRL $(\mathbf{a}, \mathbf{b})$ as well as ACTH $(\mathbf{c}, \mathbf{d})$ in lactating rats. Each value represents the mean \pm SEM of 5-6 lactating (separated for $4 \mathrm{~h}$ ) mothers per group. Statistical significance compared to matched BRC group: ${ }^{*} \mathrm{p}<$ $0.05 ;{ }^{* *} \mathrm{p}<0.001$.

$\alpha-\mathrm{MSH}$ is cleaved from ACTH and subsequently $\mathrm{N}$-acetylated to form the biologically active $\alpha-\mathrm{MSH}$. Many reports $[4,21,42,43]$, including those from our laboratory [30], indicate that hypothalamic NEDA neurons exert tonic inhibitory control over the processing and secretion of $\alpha$-MSH from the IL. Moreover, it has been demonstrated in vitro that DA diminishes the spontaneous release of $\alpha-\mathrm{MSH}$ from this lobe [44]. In contrast, there is a significant reduction in the DA concentration in both IL and NL of lactating rats due to suckling stimulus, without a change in plasma levels of $\alpha$-MSH [20,30]. Based on these observations and the present data, we can speculate that $\mathrm{ACTH}$ secretion is regulated, at least in part, by NEDA neurons, and a diminished pool of DA in the terminals of PHDA and/or THDA neurons of lactating mothers might be a cause of the change of IL ACTH (elevated) and $\alpha$-MSH (reduced) concentrations. To further investigate this possibility we have used 3 different approaches.

First, the levels of DA and its main metabolite DOPAC were measured in lactating and OVX rats. Lower concentrations of DA were detected in the IL as well as in the NL of lactating compared to OVX rats (table 1), suggesting a causative role in both the elevation of IL ACTH and reduction of $\alpha$-MSH.

Second, for pharmacological approaches to investigate the direct control by DA on ACTH secretion in lactating 


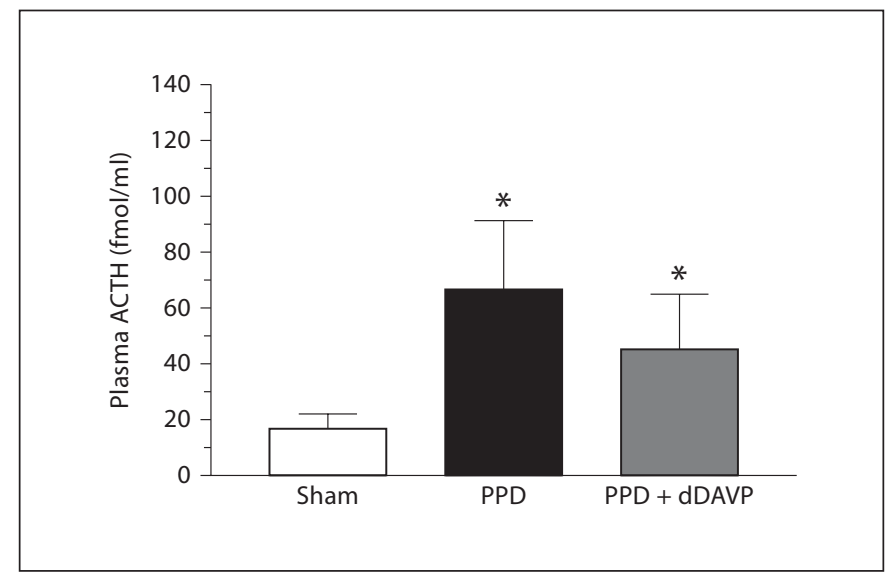

Fig. 6. PPD increases ACTH level in the plasma of lactating dams. dDAVP replacement that completely prevents diabetes insipidus does not influence the elevated basal ACTH secretion. Each value represents the mean \pm SEM of 5 lactating (separated for $4 \mathrm{~h}$ ) rats per group. Statistical significance compared to the sham-operated group: * $\mathrm{p}<0.05$.

rats, we used compounds that are known to affect DA transmission of NEDA neurons [13]. As expected, we found that similar to the suckling stimulus, inhibition of DA biosynthesis in NEDA neurons by $\alpha \mathrm{MpT}$ and/or blockade of D2R located on both lactotropes and melanotropes by DOM led to elevated plasma levels of PRL and $\mathrm{ACTH}$, but did not influence plasma $\alpha-\mathrm{MSH}$ concentrations in lactating animals (fig. 4). The same treatments, however, have no effect on ACTH release in OVXor OVX $+\mathrm{E}_{2}$-treated rats, but in parallel with PRL, they have elevated plasma $\alpha$-MSH concentrations (fig. 4). It should be emphasized again that DA levels are significantly reduced in the IL of lactating rats compared to OVX animals, and the lack of effect of $\alpha \mathrm{MpT}$ and DOM on plasma $\alpha-\mathrm{MSH}$ could be simply due to this reduced DA tone. This possibility remains to be investigated. The role of hypophysiotropic NEDA neurons in the secretory response of ACTH induced by either $\alpha \mathrm{MpT}$ or DOM has been further confirmed by the observation that the selective $\mathrm{D} 2 \mathrm{R}$ agonist, BRC, was able to block both $\alpha \mathrm{MpT}$ - and DOM-induced elevation of plasma ACTH as well as PRL only in lactating animals (fig. 5). These findings clearly indicate that the NEDA system, or at least one of its subpopulations, as well as $\mathrm{D} 2 \mathrm{R}$ is involved in the regulation of ACTH secretion in lactating mothers. Nevertheless, D2Rs are not found in pituitary corticotropes [1, 45], although this aspect has not been investigated in pituitary glands of lactating rats.

Dopamine-Regulated ACTH Secretion in Lactating Rats
Third, to test whether a functionally active DA pool is retained in the IL and NL of nursing mothers, surgical disruption of nerve fibers passing through the stalk and terminating in these two lobes of the pituitary gland were performed. This so-called posterior pituitary (IL $+\mathrm{NL}$ ) denervation has already been shown to disrupt the axons of both the THDA and the PHDA neurons, while leaving TIDA neurons and vascular supply of the AL intact [30, 37]. The expression of tyrosine hydroxylase was diminished following PPD in lactating dams [30], and the concentration of DA and DOPAC in both the IL and NL was shown to be significantly reduced after PPD in OVX rats [37]. In parallel with this, elevated plasma levels of PRL and $\alpha$-MSH (similar to D2R knockout animals) were detected [37]. Our present data clearly demonstrate that disruption of DAergic innervation of the IL results in an elevated basal level of ACTH (fig. 6). These data are in line with all previous results, showing that tonic inhibitory regulation of ACTH occurs in lactating rats.

The importance of DA in POMC synthesis and processing has been described previously. Haloperidol (D2R antagonist) treatment increases PC1, PC2 and POMC expression in the IL, whereas BRC has the opposite effect [46]. Expression of functioning D2Rs in ACTH-secreting pituitary tumors has also been observed [47]. Moreover, treatment with the DA agonist cabergoline normalized the high plasma ACTH as well as cortisol levels in the majority of these cases [47]. Interestingly, glucocorticoid receptors are not present in the IL, but appear in this lobe following pituitary stalk transection [48]. BRC is also able to inhibit expression of glucocorticoid receptors in IL cell cultures and haloperidol is able to block this inhibitory effect, indicating an active role of DA and its $\mathrm{D} 2 \mathrm{R}$ in the processing of POMC. In contrast to the effects in IL cells, BRC does not affect glucocorticoid receptor expression in the AL cells under similar circumstances $[8,48]$. In summary, our present observations strongly suggest that a certain proportion of ACTH detected in the plasma of lactating dams is processed in and released from the IL. This plasticity in the processing of IL POMC may have great physiological significance during lactation.

It should be mentioned that alterations in neuropeptide processing by PCs during lactation is not limited to the otherwise tissue-specific cleavage in POMC of these two parts of the pituitary gland. It is known that $\mathrm{PCl}$ and PC2 play a significant role in processing of prepro-thyrotropin-releasing hormone (TRH) of the hypothalamic $\mathrm{PVN}$. PC1 is the major contributor in pro-TRH processing [49], while PC2 has a specific role in cleaving of TRH 
from its extended forms [50]. Changes in pro-TRH processing in PVN of lactating rats have also been detected, suggesting a physiological role for the elevation of the alternatively processed peptides in the regulation of prolactin secretion [50]. All this together may suggest that a coordinated regulation of processing of hypothalamo-pituitary neuropeptides by PCs may exist in lactating rats [51].

Several recent studies have provided clear evidence that deletion of crucial players of the inhibitory regulation and/or processing of IL POMC, such as D2R, PC2, or the chaperone molecule $7 \mathrm{~B} 2$, has similar, but quantitatively different consequences [25-27, 47, 52], including the elevation of ACTH content in the IL and circulating ACTH levels. For example, in 7B2-null mice [26], inactivation of PC2 leads to failure to generate $\alpha-\mathrm{MSH}$ in the $\mathrm{IL}$, resulting in very high levels of ACTH resembling those in pituitary Cushing's disease. Interestingly, the 7B2-null mice contain only a quarter of the normal levels of DA. It is presumed that a diminished pool of DA in the nerve endings in both the IL and the NL of 7B2-null mice is likely involved in the enhanced secretion of ACTH [27]. Secretion of $\alpha-\mathrm{MSH}$ and ACTH from transplanted pituitary IL in stressed as well as nonstressed rats was shown more than a decade ago [53]. Administration of ergocryptine (a DA agonist) to these nonstressed grafted rats induced a decrease in plasma ACTH levels, indicating that the grafts contributed to the complement of circulating ACTH. Comparison of the ratios of both hormones re- leased in incubations showed that grafts secreted more ACTH than $\alpha-\mathrm{MSH}$. The present data are compatible with these earlier observations. The potential link between the function of 7B2 and pituitary catecholamines in the physiological regulation of POMC processing in the AL and the IL needs to be clarified.

In conclusion, the majority of $\mathrm{ACTH}$, detected in the plasma of lactating dams, appears to originate from the IL. Furthermore, differences in ACTH and $\alpha-\mathrm{MSH}$ responses between OVX and lactating females indicate the existence of a physiologically important plasticity of melanotropes in the IL of the pituitary gland. Consequently, reconsideration of the generally accepted view of the tissue-specific processing of POMC may be required. It is tempting to speculate that this change in function of IL melanotropes may be physiologically relevant to the homeostasis of the nursing mothers. For example, the elevated basal ACTH concentration accompanied by a blunted corticosterone rhythm [32], and decreased responsiveness to stress $[33,34]$ may be components of an adaptation process, i.e. a solution of a physiological challenge, required during this period of life. This proposition requires further investigation.

\section{Acknowledgements}

This work was supported by the Hungarian National Research Fund (OTKA 68170 to G.M.N.), by the Ministry of Health (ETT $114 / 97$ to M.V.) and by NIH DK43200.

\section{References}

$>1$ Chen CL, Dionne FT, Roberts JL: Regulation of the pro-opiomelanocortin mRNA levels in rat pituitary by dopaminergic compounds. Proc Natl Acad Sci USA 1983;80:2211-2215.

$>2$ Lundblad JR, Roberts JL: Regulation of proopiomelanocortin gene expression in pituitary. Endocr Rev 1988;9:135-158

$\checkmark 3$ Benjannet S, Rondeau N, Day R, Chretien M, Seidah NG: PC1 and PC2 are proprotein convertases capable of cleaving proopiomelanocortin at distinct pairs of basic residues. Proc Natl Acad Sci USA 1991;88:3564-3568.

-4 Day R, Schafer MK, Watson SJ, Chretien M, Seidah NG: Distribution and regulation of the prohormone convertases PC1 and PC2 in the rat pituitary. Mol Endocrinol 1992;6: 485-497.

$>5$ Meunier H, Lefevre G, Dumont D, Labrie F: CRF stimulates alpha-MSH secretion and cyclic AMP accumulation in rat pars intermedia cells. Life Sci 1982;31:2129-2135.

$\checkmark 6$ Aguilera G: Regulation of pituitary ACTH secretion during chronic stress. Front Neuroendocrinol 1994;15:321-350.
7 Pardy K, Carter D, Murphy D: Dopaminergic mediation of physiological changes in proopiomelanocortin messenger ribonucleic acid expression in the neurointermediate lobe of the rat pituitary. Endocrinology 1990; 126:2960-2964.

$>8$ Antakly T, Sasaki A, Liotta AS, Palkovits M, Krieger DT: Induced expression of the glucocorticoid receptor in the rat intermediate pituitary lobe. Science 1985;229:277-279.

$\checkmark 9$ Autelitano DJ, Snyder L, Sealfon SC, Roberts JL: Dopamine $\mathrm{D}_{2}$-receptor messenger RNA is differentially regulated by dopaminergic agents in rat anterior and neurointermediate pituitary. Mol Cell Endocrinol 1989;67:101105.

10 Mansour A, Meador-Woodruff JH, Bunzow JR, Civelli O, Akil H, Watson SJ: Localization of dopamine $\mathrm{D}_{2}$ receptor $m R N A$ and $D_{1}$ and $\mathrm{D}_{2}$ receptor binding in the rat brain and pituitary: an in situ hybridization-receptor autoradiographic analysis. J Neurosci 1990; 10:2587-2600.
11 Fuxe K: Cellular localization of monoamines in the median eminence and the infundibular stem of some mammals. Z Zellforsch Mikrosk Anat 1964;61:710-724.

12 Ben-Jonathan N: Dopamine: a prolactin-inhibiting hormone. Endocr Rev 1985;6:564589.

13 Freeman ME, Kanyicska B, Lerant A, Nagy G: Prolactin: structure, function, and regulation of secretion. Physiol Rev 2000;80: 1523-1631.

14 Demarest KT, McKay DW, Riegle GD, Moore KE: Sexual differences in tuberoinfundibular dopamine nerve activity induced by neonatal androgen exposure. Neuroendocrinology 1981;32:108-113.

15 Gunnet JW, Lookingland KJ, Moore KE: Effects of gonadal steroids on tuberoinfundibular and tuberohypophysial dopaminergic neuronal activity in male and female rats. Proc Soc Exp Biol Med 1986;183:48-53. 
16 de Greef WJ, Plotsky PM, Neill JD: Dopamine levels in hypophysial stalk plasma and prolactin levels in peripheral plasma of the lactating rat: effects of a simulated suckling stimulus. Neuroendocrinology 1981;32:229233.

17 Gunnet JW, Lookingland KJ, Moore KE: Comparison of the effects of castration and steroid replacement on incertohypothalamic dopaminergic neurons in male and female rats. Neuroendocrinology 1986;44:269-275.

18 Plotsky PM, Neill JD: The decrease in hypothalamic dopamine secretion induced by suckling: comparison of voltammetric and radioisotopic methods of measurement. Endocrinology 1982;110:691-696.

19 Bjorklund A, Moore RY, Nobin A, Stenevi U: The organization of tubero-hypophyseal and reticulo-infundibular catecholamine neuron systems in the rat brain. Brain Res 1973;51:171-191.

-20 Nagy GM, DeMaria JE, Freeman ME: Changes in the local metabolism of dopamine in the anterior and neural lobes but not in the intermediate lobe of the pituitary gland during nursing. Brain Res 1998;790:315-317.

-21 Goudreau JL, Lindley SE, Lookingland KJ, Moore KE: Evidence that hypothalamic periventricular dopamine neurons innervate the intermediate lobe of the rat pituitary. Neuroendocrinology 1992;56:100-105.

22 Asa SL, Kelly MA, Grandy DK, Low MJ: Pituitary lactotroph adenomas develop after prolonged lactotroph hyperplasia in dopamine $\mathrm{D}_{2}$ receptor-deficient mice. Endocrinology 1999;140:5348-5355.

-23 Iaccarino C, Samad TA, Mathis C, Kercret H, Picetti R, Borrelli E: Control of lactotrop proliferation by dopamine: essential role of signaling through $\mathrm{D}_{2}$ receptors and ERKs. Proc Natl Acad Sci USA 2002;99:1453014535.

-24 Kelly MA, Rubinstein M, Asa SL, Zhang G, Saez C, Bunzow JR, Allen RG, Hnasko R, Ben-Jonathan N, Grandy DK, Low MJ: Pituitary lactotroph hyperplasia and chronic hyperprolactinemia in dopamine $\mathrm{D}_{2}$ receptordeficient mice. Neuron 1997;19:103-113.

-25 Saiardi A, Borrelli E: Absence of dopaminergic control on melanotrophs leads to Cushing's-like syndrome in mice. Mol Endocrinol 1998;12:1133-1139.

26 Westphal CH, Muller L, Zhou A, Zhu X, Bonner-Weir S, Schambelan M, Steiner DF, Lindberg I, Leder P: The neuroendocrine protein 7B2 is required for peptide hormone processing in vivo and provides a novel mechanism for pituitary Cushing's disease. Cell 1999;96:689-700.

-27 Laurent V, Kimble A, Peng B, Zhu P, Pintar JE, Steiner DF, Lindberg I: Mortality in 7B2 null mice can be rescued by adrenalectomy: involvement of dopamine in ACTH hypersecretion. Proc Natl Acad Sci USA 2002;99: 3087-3092.

28 Khorram O, Bedran deCastro JC, McCann SM: The influence of suckling on the hypothalamic and pituitary secretion of immunoreactive alpha-melanocyte stimulating hormone. Brain Res 1986;398:361-365.
29 Nagy GM, Vecsernyés M, Julesz J, Barna I, Koenig JI: Dehydration decreases plasma level of alpha-melanocyte-stimulating hormone (alpha-MSH) and attenuates suckling induced beta-endorphin but not ACTH response in lactating rats. Neuroendocrinol Lett 1994;16:275-284.

30 Vecsernyes M, Krempels K, Toth BE, Julesz J, Makara GB, Nagy GM: Effect of posterior pituitary denervation (PPD) on prolactin (PRL) and alpha-melanocyte-stimulating hormone (alpha-MSH) secretion of lactating rats. Brain Res Bull 1997;43:313-319.

31 Vecsernyes M, Nagy G, Meszaros L, Bodnar L, Ahmed KW, Toth R, Julesz J, Nagy GM: Suckling-induced change in oxytocin but not in alpha-MSH concentrations of the median eminence, the neural-, intermediateand anterior lobes of the pituitary gland. Endocr Res 2000;26:333-345.

- 32 Walker CD, Lightman SL, Steele MK, Dallman MF: Suckling is a persistent stimulus to the adrenocortical system of the rat. Endocrinology 1992;130:115-125.

- 33 Windle RJ, Wood S, Shanks N, Perks P, Conde GL, da Costa AP, Ingram CD, Lightman SL: Endocrine and behavioural responses to noise stress: comparison of virgin and lactating female rats during non-disrupted maternal activity. J Neuroendocrinol 1997;9:407-414.

34 Banky Z, Nagy GM, Halasz B: Analysis of pituitary prolactin and adrenocortical response to ether, formalin or restraint in lactating rats: rise in corticosterone, but no increase in plasma prolactin levels after exposure to stress. Neuroendocrinology 1994; 59:63-71.

35 Horvath KM, Banky Z, Toth BE, Halasz B, Nagy GM: Effect of adrenalectomy and dexamethasone treatment on prolactin secretion of lactating rats. Brain Res Bull 2001;56:589592.

36 Wise PM, Rance N, Barraclough CA: Effects of estradiol and progesterone on catecholamine turnover rates in discrete hypothalamic regions in ovariectomized rats. Endocrinology 1981;108:2186-2193.

37 DeMaria JE, Zelena D, Vecsernyes M, Nagy GM, Freeman ME: The effect of neurointermediate lobe denervation on hypothalamic neuroendocrine dopaminergic neurons. Brain Res 1998;806:89-94.

38 Lowry OH, Rosebrough NJ, Farr AL, Randall RJ: Protein measurement with the Folin phenol reagent. J Biol Chem 1951;193:265275.

- 39 Kacsoh B, Veress Z, Toth BE, Avery LM, Grosvenor CE: Bioactive and immunoreactive variants of prolactin in milk and serum of lactating rats and their pups. J Endocrinol 1993; 138:243-257.

40 Vecsernyes M, Julesz J: Specific radioimmunoassay of alpha-melanocyte-stimulating hormone in rat plasma. Exp Clin Endocrinol 1989;93:45-51.

41 Barna I, Koenig JI: Effects of mediobasal hypothalamic lesion on immunoreactive $\mathrm{ACTH} /$ beta-endorphin levels in cerebrospinal fluid, in discrete brain regions, in plas- ma, and in pituitary of the rat. Brain Res 1992;593:69-76.

42 Chronwall BM, Hook GR, Millington WR: Dopaminergic regulation of the biosynthetic activity of individual melanotropes in the rat pituitary intermediate lobe: a morphometric analysis by light and electron microscopy and in situ hybridization. Endocrinology 1988;123:1992-2002.

43 Cote TE, Eskay RL, Frey EA, Grewe CW, Munemura M, Stoof JC, Tsuruta K, Kebabian JW: Biochemical and physiological studies of the beta-adrenoceptor and the $\mathrm{D}_{2}$ dopamine receptor in the intermediate lobe of the rat pituitary gland: a review. Neuroendocrinology 1982;35:217-224.

44 Munemura M, Cote TE, Tsuruta K, Eskay RL, Kebabian JW: The dopamine receptor in the intermediate lobe of the rat pituitary gland: pharmacological characterization. Endocrinology 1980;107:1676-1683.

45 Chronwall BM, Millington WR, Griffin WS, Unnerstall JR, O'Donohue TL: Histological evaluation of the dopaminergic regulation of proopiomelanocortin gene expression in the intermediate lobe of the rat pituitary, involving in situ hybridization and $[3 \mathrm{H}]$ thymidine uptake measurement. Endocrinology 1987; 120:1201-1211.

46 Oyarce AM, Hand TA, Mains RE, Eipper BA: Dopaminergic regulation of secretory granule-associated proteins in rat intermediate pituitary. J Neurochem 1996;67:229241.

47 Pivonello R, Ferone D, de Herder WW, Faggiano A, Bodei L, de Krijger RR, Lombardi G, Colao A, Lamberts SW, Hofland LJ: Dopamine receptor expression and function in corticotroph ectopic tumors. J Clin Endocrinol Metab 2007;92:65-69.

48 Antakly T, Mercille S, Cote JP: Tissue-specific dopaminergic regulation of the glucocorticoid receptor in the rat pituitary. Endocrinology 1987;120:1558-1562.

-49 Schaner P, Todd RB, Seidah NG, Nillni EA Processing of prothyrotropin-releasing hormone by the family of prohormone convertases. J Biol Chem 1997;272:19958-19968.

50 Nillni EA, Aird F, Seidah NG, Todd RB, Koenig JI: PreproTRH(178-199) and two novel peptides (pFQ7 and pSE14) derived from its processing, which are produced in the paraventricular nucleus of the rat hypothalamus, are regulated during suckling. Endocrinology 2001;142:896-906.

-51 Nillni EA: Regulation of prohormone convertases in hypothalamic neurons: implications for prothyrotropin-releasing hormone and proopiomelanocortin. Endocrinology 2007;148:4191-4200.

- 52 Laurent V, Jaubert-Miazza L, Desjardins R, Day R, Lindberg I: Biosynthesis of proopiomelanocortin-derived peptides in prohormone convertase 2 and 7B2 null mice. Endocrinology 2004;145:519-528.

53 Iturriza FC, Eberle AN: Secretion of melanocyte-stimulating hormone and adrenocorticotropin from transplanted pituitary pars intermedia in stressed and nonstressed rats. Neuroendocrinology 1989;49:610-616. 